\title{
Female mating preferences in blind cave tetras Astyanax fasciatus (Characidae, Teleostei)
}

\author{
Martin Plath ${ }^{1,2,3)}$, Matthias Rohde ${ }^{4)}$, Thekla Schröder ${ }^{5)}$, Angelika \\ Taebel-Hellwig ${ }^{5)}$ \& Ingo Schlupp ${ }^{2)}$ \\ $\left({ }^{1}\right.$ Abteilung für Evolutionsbiologie/Spezielle Zoologie, Institut für Biochemie/Biologie der \\ Universität Potsdam, Karl-Liebknecht-Str. 24-26, 14476 Potsdam, Germany; ${ }^{2}$ Department \\ of Zoology, University of Oklahoma, 730 Van Vleet Oval, Norman, OK 73019, USA; \\ ${ }^{4}$ Department Biologie II, Ludwig-Maximilians-Universität, Planegg-Martinsried, Germany; \\ ${ }^{5}$ Universität Hamburg, Biozentrum Grindel, Abteilung für Verhaltensbiologie, \\ Martin-Luther-King Platz 3, 20146 Hamburg, Germany)
}

(Accepted: 6 September 2005)

\begin{abstract}
Summary
The Mexican tetra Astyanax fasciatus has evolved a variety of more or less color- and eyeless cave populations. Here we examined the evolution of the female preference for large male body size within different populations of this species, either surface- or cave-dwelling. Given the choice between visual cues from a large and a small male, females from the surface form as well as females from an eyed cave form showed a strong preference for large males. When only non-visual cues were presented in darkness, the surface females did not prefer either males. Among the six cave populations studied, females of the eyed cave form and females of one of the five eyeless cave populations showed a preference for large males. Apparently, not all cave populations of Astyanax have evolved non-visual mating preferences. We discuss the role of selection by benefits of non-visual mate choice for the evolution of non-visual mating preferences.
\end{abstract}

Keywords: cave fish, sensory shift, mate choice, sexual selection.

\section{Introduction}

Most evolutionary studies focus on adaptive processes, i.e., evolutionary change in response to selection. There are, however, scenarios like genetic

\footnotetext{
3) Corresponding author's e-mail address: martin_plath@web.de 
drift that may cause evolutionary change in the absence of selection (e.g., Futuyma, 1998; Freeman \& Herron, 2001). Since Darwin (1859), cave animals are of prime interest to study both constructive and regressive evolution. Cave dwellers are unique models to study regressive features like the reduction of eyes and pigments (Culver \& Wilkens, 2000 for a review). It seems straightforward to assume relaxed/neutral selection on the visual apparatus and body coloration when vision becomes obsolete due to the absence of light (but see Culver, 1982; Culver et al., 1995; Jeffery, 2005). However, the colonization of constantly lightless subterranean habitats by formerly surface-dwelling species unambiguously leads to drastic changes in the direction of several selection pressures (Culver et al., 1995; see also Caccone \& Sbordoni, 2001; Borowsky \& Wilkens, 2002). For example, in the absence of vision cave-dwellers need to rely on non-visual orientation, food localization and predator detection. In cave-living fishes, elongated sensitive body appendices like fins (e.g., balitorid loach, Triplophysa gejiuensis: Chu \& Chen, 1979) or barbels (e.g., pimelodid catfish, Rhamdia spp.: Wilkens, 2001), and an improved gustatory sense (e.g., Poecilia mexicana, Poeciliidae: Parzefall, 1970; Astyanax fasciatus, Characidae: Schemmel, 1967) have been described. Cave fishes may also modify their mechanosensory lateral line by widened canal pores (P. mexicana: Parzefall, 1970; Cottus carolinae, Cottidae: Burr et al., 2001) or by enlarging the cupulae of their superficial neuromasts (A. fasciatus: Teyke, 1990).

Cave-dwelling Mexican tetras, Astyanax fasciatus (Characidae) are the most frequently used model organisms in studies on cave-fish biology (e.g., Romero, 1985; Wilkens, 1988; Behrens et al., 1997; Yamamoto \& Jeffery, 2000; Jeffery, 2001; Borowsky \& Wilkens, 2002; Romero et al., 2003; Wilkens \& Strecker, 2003; Yamamoto et al., 2004). The genus Astyanax is very species rich and widespread in Central and South American freshwaters (Alvarez, 1946; Miller, 1986; Reis et al., 2003; see Strecker et al., 2004 for a recent phylogeographic study). River-dwelling fish are grayish in color with a typical counter-shading dark melanin pigmentation on the back. The abdomen is whitish-silver due to guanin pigmentation. Surface fish posses large eyes and mostly form schools. In shallow areas they may form temporary territories (Parzefall, 1983). Astyanax feed on a variety of food sources (Bussing, 1998; Vilella et al., 2002).

More than 30 cave populations have been described (Mitchell et al., 1977; Espinasa et al., 2001), primarily from the Sierra de El Abra, San Louis Potosí 
and Tamaulipas in Northeast-Mexico (Mitchell et al., 1977). Some cave populations are also found north in the neighboring Sierra de Guatemala, west in the Sierra de Colmena, but also in a geographically distant cave, the Gruta de las Granadas (region of Guerrero, West-central Mexico; Espinasa et al., 2001). Most of the cave forms are characterized by conspicuous morphological and behavioral changes such as the reduction of eyes and pigmentation (Wilkens, 1988) as well as reduced schooling (Parzefall, 1993a) and reduced aggressive behavior (Parzefall \& Hausberg, 2001; Espinasa et al., 2001). It has been assumed that different degrees in such reduction processes indicate different time-spans of separation from the surface, where the completely blind and white forms represent phylogenetically old cave forms (Wilkens \& Burns, 1972; Peters et al., 1975; Wilkens \& Strecker, 2003).

Few studies have investigated the evolution of intersexual communication for mate choice in cave-dwellers (Plath et al., 2003, 2004, 2005). Sensory systems that enable non-visual orientation, food finding, etc. must be well developed in all cave fishes. However, how do improved non-visual sensory capabilities relate to female mate choice? In the Atlantic molly Poecilia mexicana (Poeciliidae), surface-living females have a mating preference for large males (Plath et al., 2003, 2004). Unlike the surface females, cave-dwelling females from the South Mexican Cueva del Azufre prefer to associate with the larger of two males even in the absence of visible light. Apparently, this mating preference is mediated by visual cues in the surface form. The preference has persisted in the cave form, but cave-dwelling females use non-visual cues to determine male size, and a sensory shift has occurred (Plath et al., 2003, 2004).

So far it is unclear whether sexual preferences in cave animals evolve as a by-product of selection on improved sensory capabilities or as specific adaptations to the situation in certain caves. Because all cave populations of $A$. fasciatus are likely to have convergently evolved/improved non-visual sensory capabilities and/or have stronger representation of non-visual information in the higher processing, all populations should be similar in their preferences, whereas specific adaptations should vary with the ecology of the individual caves.

The cave populations of A. fasciatus provide an excellent tool for a comparative approach to this question. In this study we asked if non-visual mating preferences occur in different cave populations of A. fasciatus. At least some cave forms of $A$. fasciatus are assumed to represent independent 
cave colonization events (Espinasa \& Borowsky, 2001; Dowling et al., 2002; Strecker et al., 2003; Wilkens \& Strecker, 2003). We investigated female mating preferences for large male body size in seven populations of $A$. fasciatus, either surface- or cave-dwelling. To our knowledge, this is the first study of mating preferences within the genus Astyanax.

We had access to laboratory stocks from six cave populations, five of which are completely white and eyeless. In one population (Micos), variable degrees in the reduction of eyes and/or pigmentation are found. Eyed Micos cave fish allowed us to observe whether these females are still able to base their mate choice decisions on visual cues. In all populations, we tested for non-visual mating preferences relative to male body size. Specifically, we asked: (1) Do surface-dwelling A. fasciatus females exhibit a visual mating preference for large males? (2) Do eyed cave females also show a visual preference? (3) Do cave-dwelling females have a preference for large males, and do they express this preference using non-visual cues, i.e. under naturally dark conditions? We predicted a visual preference in all eyed females, because visual mating preferences for large male size appear to be almost ubiquitous (Ryan \& Keddy-Hector, 1992; Andersson, 1994). Females may benefit from mating with large males, for example because male size and sperm availability are typically positively correlated (e.g., genus Poecilia: Aspbury \& Gabor, 2004; Schlupp \& Plath, 2005). Based on the finding that surface-dwelling Atlantic molly females (P. mexicana) do not use non-visual cues in mate choice, but cave molly females do so (Plath et al., 2004, 2005), we predicted that only A. fasciatus females from the cave populations would exhibit a mating preference in darkness.

\section{Material and methods}

\section{Study organisms and housing conditions}

Test fish came from laboratory reared stocks of seven different populations of A. fasciatus. The cave populations stem from different caves in San Louis Potosí and Tamaulipas (Table 1; for detailed descriptions of the caves and maps see Mitchell et al., 1977; Wilkens, 1988; Strecker et al., 2003). We had access to one surface-population, which was collected in a creek near the Micos cave. Stocks comprising both sexes were maintained in 100-200 1 aquaria at $25 \pm 1^{\circ} \mathrm{C}$ under a 12:12 hour light-dark cycle. All stocks had 
Table 1. Origin of the cave populations studied.

\begin{tabular}{|c|c|c|}
\hline Mountain chain & Site & Population \\
\hline $\begin{array}{l}\text { Sierra de Colmena (west of the } \\
\text { Sierra de El Abra) }\end{array}$ & $\begin{array}{l}\text { La Cueva del Río Subterráneo, } \\
\text { app. } 30 \mathrm{~km} \text { west of Ciudad Valles }\end{array}$ & Micos \\
\hline $\begin{array}{l}\text { Sierra de Guatemala (north of } \\
\text { the Sierra de El Abra) }\end{array}$ & El Sótano de Molino & Molino \\
\hline Northern Sierra de El Abra & $\begin{array}{l}\text { La Cueva de El Pachón, } \\
\text { app. } 20 \mathrm{~km} \text { SW of Ciudad Mante }\end{array}$ & Pachon \\
\hline Central Sierra de El Abra & $\begin{array}{l}\text { El Sótano de Yerbaniz, } \\
\text { app. } 25 \mathrm{~km} \text { north of Ciudad Valles }\end{array}$ & Yerbaniz \\
\hline \multirow[t]{2}{*}{ Southern Sierra de El Abra } & $\begin{array}{l}\text { El Sótano de las Piedras, } \\
\text { app. } 10 \mathrm{~km} \text { NE of Ciudad Valles }\end{array}$ & Piedras \\
\hline & $\begin{array}{l}\text { Cueva de la Curva, } \\
\text { app. } 8 \mathrm{~km} \text { east of Ciudad Valles }\end{array}$ & Curva \\
\hline
\end{tabular}

identical rearing conditions. Fish were fed twice a day ad libitum with flake food, occasionally supplemented with live Tubifex worms or water fleas. Males and females were kept in separate tanks for one week prior to the tests and water was frequently renewed. This procedure activates reproductive behavior in A. fasciatus, i.e. the motivation to spawn (Wilkens, pers. comm.). Males could easily be recognized by the numerous small serrae on their anal fin rays. For the tests with the Micos cave fish, only completely eyed specimens (both females and males) showing a fright reaction to rapid hand movements in front of the aquarium were used.

\section{Choice tests}

For the choice tests, we used a standard test aquarium $(100 \times 35 \times 35 \mathrm{~cm})$, filled to two thirds with aged water of $25 \pm 1{ }^{\circ} \mathrm{C}$ (mean $\pm \mathrm{SD}$ ). Both sides and the back were covered with dark plastic foil. The aquarium was visually divided into three compartments of equal size: a central neutral zone and two adjacent preference zones. We placed a cylinder in the middle of each preference zone to hold the stimulus males. Females could freely swim around the cylinders. We used association times to determine mating preferences of the females. Association times are widely used to determine female mating preferences in fishes (e.g., poeciliids: Kodric-Brown, 1992; cichlids: Couldridge \& Alexander, 2001; blennies: Gonçalves \& Oliveira, 2003). Before each trial, two mature males that differed in size (Table 2 ) were randomly introduced 
Table 2. Standard lengths (SL, mean $\pm \mathrm{SD}$ ) of the test females and the stimulus males used and mean size difference between the two stimulus males.

\begin{tabular}{lllccc}
\hline Population & Experiment & SL female & $\begin{array}{c}\text { SL large } \\
\text { male }\end{array}$ & $\begin{array}{c}\text { SL small } \\
\text { male }\end{array}$ & $\begin{array}{c}\text { Size } \\
\text { difference }\end{array}$ \\
\hline Surface & Visual cues & $51.6 \pm 7.1$ & $56.4 \pm 5.3$ & $44.8 \pm 3.0$ & $11.6 \pm 2.4$ \\
& Non-visual cues & $52.9 \pm 7.4$ & $56.0 \pm 5.0$ & $43.5 \pm 3.8$ & $12.5 \pm 7.0$ \\
Micos & Visual cues & $65.7 \pm 15.1$ & $64.3 \pm 0.6$ & $42.3 \pm 0.6$ & $22.0 \pm 0.2$ \\
& Non-visual cues & $61.5 \pm 10.8$ & $67.9 \pm 8.5$ & $47.4 \pm 5.5$ & $20.6 \pm 6.2$ \\
Molino & & $57.2 \pm 6.0$ & $59.0 \pm 1.4$ & $43.6 \pm 2.8$ & $15.4 \pm 3.0$ \\
Pachon & & $44.7 \pm 3.4$ & $49.9 \pm 3.9$ & $38.3 \pm 1.5$ & $11.6 \pm 3.9$ \\
Yerbaniz & & $50.9 \pm 2.9$ & $55.1 \pm 3.6$ & $39.4 \pm 2.3$ & $15.8 \pm 4.5$ \\
Piedras & & $54.1 \pm 7.2$ & $57.4 \pm 5.8$ & $41.9 \pm 3.8$ & $15.9 \pm 3.8$ \\
Curva & & $48.0 \pm 7.4$ & $51.8 \pm 2.5$ & $35.7 \pm 3.2$ & $16.2 \pm 4.5$ \\
\hline
\end{tabular}

into one of the cylinders each. Males were given five minutes for acclimatization. Almost all males immediately started to swim calmly when introduced into the cylinders. To initiate a trial, a female was gently introduced into the middle compartment. After another five minutes, the time the female spent in either preference zone was measured for ten minutes. Then, the left and right cylinders were gently interchanged. The female was not removed during this procedure. After another five minutes, measurement was repeated accordingly for ten minutes. This procedure enabled us to detect side biases. During the tests under infrared conditions, changing of the stimuli was performed in darkness with the help of infrared goggles.

\section{Female choice using visual information}

In one experiment, surface and Micos cave females were presented with visual cues of two males. During these tests, illumination was provided by a $30 \mathrm{~W}$ neon fluorescent light above the tank. To provide optimal visibility of the stimulus males for the test female, males were confined to transparent Plexiglas cylinders (13.5 cm diameter). The observer was sitting quietly behind a black curtain facing the tank from approximately $1 \mathrm{~m}$. The fish were observed through a small hole in the curtain.

\section{Female choice using non-visual information}

In another experiment, surface and cave females were presented with nonvisual cues from the males. During these tests, the stimulus males were 
confined to wire mesh cylinders $(14 \mathrm{~cm}$ diameter; wire diameter $1 \mathrm{~mm}$; mesh-width $5 \mathrm{~mm}$ ), which allowed non-visual cues to pass through. Tests with the surface form and with the Micos cave form, which are eyed and thus capable of perceiving visual cues, were carried out using an infrared bulb $(500 \mathrm{~W})$ above the test tank. The eye of A. fasciatus is not sensitive for IR light (Parry et al., 2003). These trials were recorded with an IR-sensitive camera and monitored in an adjacent room, where the trials were scored directly. Since the eyeless blind cave fish could not see the stimulus fish even in light, these trials were conducted under diffuse room illumination, while the observer was sitting quietly approximately $1 \mathrm{~m}$ from the aquarium. Each individual of the surface and Micos cave form was tested in only one experiment (either with visual or with non-visual cues available).

\section{Sex recognition in Yerbaniz females}

We controlled whether the females perceived information concerning gender during the tests. Since the Yerbaniz females showed a preference for large males in the latter experiment, these females were also tested for sex discrimination. Tests were carried out using wire-mesh cylinders again, but two equally sized stimulus fish of both sexes were used (males: $53.3 \pm 3.7 \mathrm{~mm}$; females: $53.3 \pm 2.4 \mathrm{~mm}$; mean size difference: $1.0 \pm 0.1 \mathrm{~mm}$; focus female size: $54.2 \pm 6.0 \mathrm{~mm}$ ). Due to a limited number of individuals in the stocks, some specimens from the experiment on size-discrimination were re-used in this experiment. However, both experiments were 6 months apart, hence it is unlikely that the previous experiment has influenced the results of this experiment.

\section{Statistical analysis}

We summed up the times a female spent with the large and with the small male during both parts of a trial. We a priori decided to exclude trials in which a female spent more than $80 \%$ of the overall preference time in only one of the preference zones (side-biases). Trials in which females spent less than $50 \%$ of their total time in the preference zones would have been discarded due to low response. However, no trial had to be discarded due to these criteria. Since data were not distributed normally, we used nonparametric statistics throughout. Our intention was to determine character states, i.e., to determine whether the females of a given population prefer 


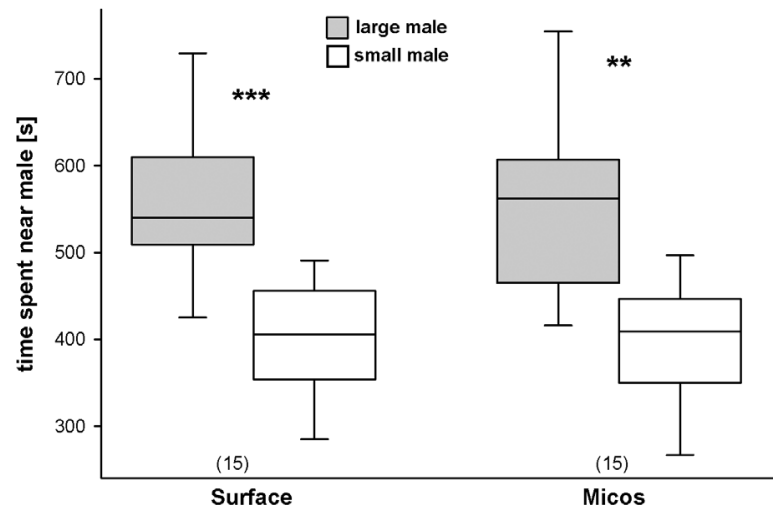

Figure 1. The relative time Astyanax fasciatus females spent in the proximity of a large male (shaded bars) or a small male (open bars). Boxplots, showing the median (middle line), the interquartile range (box) and the 5 and $95 \%$ values (whiskers). Two stimulus males were presented simultaneously in clear Plexiglas cylinders under illumination with visible light. Left: females from the surface population, right: eyed cave-dwelling females from the Micos cave. Sample sizes $(N)$ are given in brackets. Wilcoxon signed-rank test, two-tailed;

$$
{ }^{* *} p<0.01,{ }^{* * *} p<0.001 \text {. }
$$

large males or not. Therefore, we compared the times females spent associating with either type of males using Wilcoxon signed-rank tests within each population. Furthermore, we asked whether the populations would differ in the strength at which females prefer large over small males. We calculated the strength of preference for each female as: (time near large male - time near small male)/(time large + time small), where +1 would indicate maximum preference for large males, -1 would indicate maximum preference for small males and 0 would indicate no preference. We used a Mann-Whitney $U$-test to compare the response of females from the two eyed populations to visual cues. A Kruskal-Wallis ANOVA on ranks was employed to compare the response of females from the different populations in the non-visual cues experiment.

\section{Results}

\section{Female preferences using visual cues}

Given the choice between a large and a small male in light, females from the surface population and eyed females from the Micos cave spent significantly more time near the larger male (Wilcoxon signed-rank test: Surface: $z=$ 


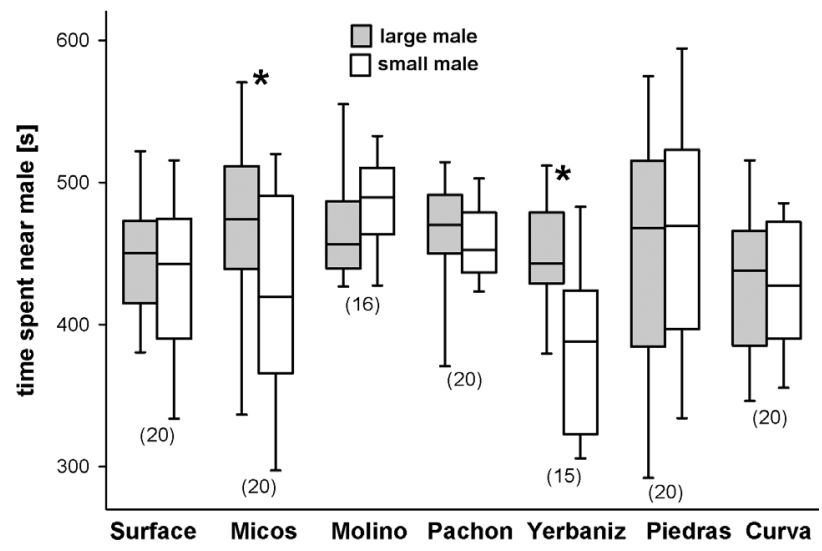

Figure 2. The relative time Astyanax fasciatus females spent close to a large (shaded bars) or a small male (open bars) in darkness. Two males differing in size were presented in wiremesh cylinders under infrared illumination (in the case of eyed females) or under dim roomillumination (eyeless females). For boxplots see Figure 1. From left to right: surface females, eyed cave-dwelling females (Micos cave, Sierra de Colmena) and eyeless cave populations: Piedras, Pachon, Yerbaniz, Molino, Curva (Sierra de El Abra and Sierra de Guatemala). Sample sizes $(N)$ are given in brackets. Wilcoxon signed-rank test, two-tailed; ${ }^{*} p<0.05$.

$-3.07, N=15, p<0.001$; Micos: $z=-2.90, N=15, p=0.002$; Figure 1). The two populations did not differ in their strength of preference (Mann-Whitney $U$-test: $T=230, p=0.93$ ).

\section{Female preferences using non-visual cues}

When only non-visual cues from the stimulus males could be perceived, females from the different populations showed variable behavior: The surface females showed no preference (Wilcoxon signed-rank test: $z=-0.90$, $N=20, p=0.39$; Figure 2). In contrast, females from the Micos cave population exhibited a preference for the larger male in darkness $(z=-1.98$, $N=20, p=0.048$ ). Among the eyeless cave populations, only Yerbaniz females showed a preference for large males $(z=-2.39, N=15$, $p=0.015)$. The females from the other populations showed no preference (Molino: $z=-1.29, N=16, p=0.21$; Pachon: $z=-0.86, N=20$, $p=0.41$; Piedras: $z=-0.07, N=20, p=0.96$; Curva: $z=-0.49$, $N=20, p=0.62$; Fig. 2). The strength of preference tended to differ between populations, but the difference was not significant (Kruskal-Wallis ANOVA on ranks: $\left.H_{6}=10.78, p=0.096\right)$. Post hoc pair-wise compar- 
isons demonstrated that Piedras females differed from the Micos (Dunn's test: $p=0.043)$ and the Yerbaniz females $(p=0.039)$.

Sex recognition and sex-specific association in Yerbaniz females

Yerbaniz females spent significantly more time near the male (median 499 (54 interquartile range, IQR) s) than near the equally sized female (426 (36 IQR) s; Wilcoxon signed-rank test: $z=-3.26, N=16, p=0.0011)$.

\section{Discussion}

Female preferences in light and in the dark

We offered A. fasciatus females a large and a small male in a simultaneous choice test. Surface-dwelling females and eyed cave females spent significantly more time near the large male when the tests were carried out in light. In darkness, only the females from the Micos cave and females from one among five blind cave populations (Yerbaniz) showed a preference. Apparently, surface-dwelling A. fasciatus females base their mating preferences on visual information, but not on non-visual information. This is the likely ancestral state. Possibly, the surface females did not respond to non-visual stimuli because they were not motivated to choose soon after they had been transferred into the dark test tank. However, the eyed Micos females were raised and tested under identical conditions, but these females did show a preference. Hence, non-visual mate choice is probably a novel trait in the Micos and Yerbaniz populations that is absent in the surface form. The surface females may either not be able to detect differences in male body size by using non-visual information or they do not base their mate choice decisions on this information. Our experimental design did not allow for direct body contact between the focal female and the males. Potentially, females of some cave populations can assess male size only when they can achieve direct body contact, although we believe this explanation unlikely. In any case, our data clearly indicate that females from the different cave populations studied differ in the extent to which they respond to far-field cues.

A between-population comparison revealed no significant differences in the strength of preference between the seven populations studied in the nonvisual cues experiment, and a post hoc pair-wise comparison revealed differ- 
ences only between the two cave populations in which a preference was detected (Micos and Yerbaniz) and the Piedras population. Therefore, we cannot exclude another (albeit less plausible) scenario: latent non-visual mate choice behavior might already have been present in the surface form, and the Piedras females may then have reduced the preference, whereas the Micos and Yerbaniz females have increased the preference. This scenario would imply that the surface females have — at least to a certain extent - the capability to determine male size in darkness. The surface form used in our study originated from near the Micos cave. However, this population appears not to be directly related with the cave forms; most likely, the present cave forms have derived from surface populations that have later gone extinct in this area (Strecker et al., 2003, 2004). We therefore cannot say with certainty whether non-visual mate choice was actually absent in the direct ancestors of the cave forms, but this seems very likely.

\section{Evolution of non-visual female preferences}

Among the six cave populations studied, females of only two populations (Micos, Yerbaniz) showed a mating preference for large males. The tetras studied came from laboratory stocks and may not represent the natural genetic variability, hence our data are discussed with caution. However, most cave tetra populations show naturally very low genetic variability (Avise \& Selander, 1972; Dowling et al., 2002; Strecker et al., 2003; Panaram \& Borowski, 2005).

A molecular phylogeny, based on RAPD markers, has suggested that the Sierra de El Abra cave fish (Molino, Piedras, Pachon, Yerbaniz) are more closely related to each other than to the Micos cave fish (Espinasa \& Borowsky, 2001). The Micos cave is situated in a separate mountain chain. Therefore, at least the Micos cave form has evolved completely independently (see Panaram \& Borowsky, 2005 for an analysis of gene-flow between caves). Another study using microsatellite analysis (Strecker et al., 2003) suggested that several of the cave populations have independently adapted to cave life (see also Dowling et al., 2002). In conclusion, the novel way of using non-visual cues for mate choice, leading to a non-visual female preference for large male body size, must have evolved at least twice independently in cave-dwelling A. fasciatus. We propose that the visual preference was inherited from the surface form and has persisted in these populations, but a 
sensory shift has occurred, and the sensory input necessary to trigger mate choice has changed from visual to non-visual.

Apparently, non-visual mate choice is not a general behavioral feature all cave fishes evolve in response to living in darkness. Cave fish females do not automatically switch from using visual to non-visual cues to express their mating preference as a by-product of improved non-visual sensory systems or stronger representation of non-visual information in the higher processing. Possibly, mate choice in cave fishes evolves as adaptations to the specific cave habitats, thus explaining the observed differences in association preferences between populations. For example, subterranean ecosystems can differ vastly in the availability of nutrients, namely bat guano, which is a typical food source of cave tetras (Parzefall, 1993b). An alternative explanation would be that the direct epigean ancestors of the different cave populations differed in their (visually mediated) preference for large male size. However, given the almost ubiquitous nature of the visual preference for large male size (Andersson, 1994), we tentatively assume that this was not the case.

\section{A potential mechanism: the Micos and Yerbaniz cave fish}

Due to the different stages in the reduction of eyes and pigmentation, the Micos cave form has been considered a phylogenetically young cave-dweller (Wilkens \& Burns, 1972), and the other cave populations are thought to be comparatively older cave-dwellers (Wilkens, 1988). If this assumption is true, non-visual mate choice must have evolved relatively fast in the Micos cave form, indicating strong selection. We propose the following model for the evolution of non-visual mate choice for large male size following the colonization of a cave by a population of tetras:

(1) The (visual) preference is inherited from the surface-dwelling ancestor and persists, but is initially not expressed.

(2) Simultaneously, cave conditions (constant darkness) promote the evolution of non-visual sensory systems and/or stronger representation of such information in the higher processing.

(3) Selection to express the preference by using non-visual sensory input generates non-visual mating preferences. If selection is missing, the preference may be reduced over time. Possibly, this selection also directly acts on the sensory systems involved in perceiving male traits, thereby shaping the non-visual sensory capabilities. 
In the case of the Micos and Yerbaniz cave fish, selection may be generated by a good-genes-mechanism: Large males probably indicate their ability to cope with the scarcity of food in the harsh cave environment reliably by showing body growth. This view is supported by a study showing that caveadapted fish are typically in a considerably better condition (i.e. nutritional state) than the surface fish co-occurring in the cave (Wilkens \& Burns, 1972; Wilkens \& Hüppop, 1986) and apparently out-compete the surface fish when food becomes scarce. In the Micos and Yerbaniz cave, surface-dwelling $A$. fasciatus are frequently washed into the cave from epigean habitats (Wilkens \& Hüppop, 1986; see also Panaram \& Borowsky, 2005 for a genetic analysis of migration patterns). Interestingly, few 'phenotypic hybrids' are found in these caves, although introgression of neutral genetic markers from the surface into the Micos and Yerbaniz caves is much higher than, for example, in the Curva or Molino caves (Panaram \& Borowsky, 2005). Likely, in addition to natural selection, sexual selection by female mate choice favors cave-adapted individuals in these cave systems (e.g., males which show body growth), thereby driving the evolution of cave adaptations ('troglomorphic traits').

\section{Sensory basis}

What is the sensory basis of mate choice in the absence of vision in Micos and Yerbaniz females? Firstly, olfactory signals (i.e. pheromones) may be involved. For example, female choice relative to male body size on the basis of olfactory cues has been found in salamanders (Plethodon spp.: Marco et al., 1998; Euproctus asper: Plath et al., unpubl. data). Cave-dwelling A. fasciatus have evolved increased gustatory capabilities (Schemmel, 1967, 1980; Hüppop, 1987), but so far little is known about their olfactory capabilities. Secondly, the mechanosensory lateral line is likely to be involved in nonvisual mate choice (Plath et al., 2004 for a discussion). Hydrodynamic imaging of the surrounding by using mechanosensory cues has been convincingly demonstrated for cave A. fasciatus (Hassan, 1989; Montgomery et al., 2001 for a review).

\section{Association preferences and the mating system of A. fasciatus}

Surface-dwelling A. fasciatus mostly form schools, so association preferences may actually represent schooling preferences. In contrast, the cave fish 
have strikingly reduced their schooling tendency, including the Micos cave fish (Parzefall \& Senkel, 1986; Parzefall, 1993a). Hence, schooling does not explain the observed association preferences. Furthermore, surface-dwelling fish are highly aggressive when not schooling (Breder, 1943), but cavedwelling fish have strikingly reduced aggression (Burchards et al., 1985; Parzefall \& Hausberg, 2001). Therefore, an aggressive component of the observed association preference is unlikely in the cave populations. Most importantly, when Yerbaniz females were given a choice between a male and an equally sized female under the same experimental conditions as for the mate choice tests, they significantly preferred to associate with the male. This shows that at least the females from the Yerbaniz population actively search for mates under these experimental conditions. We cannot say with certainty whether the same is true for females of the other populations. However, prior to the experiments all females had experienced frequent changing of the water of their holding tanks, which activates spawning, and the females exhibited an increased distension of their abdomen, suggesting that eggs were maturing.

A previous study has described that spawning is typically initiated by males both in surface- and in cave-dwelling tetras (Wilkens, 1972). Males chase females while keeping close body contact until the female spawns. Hence, there appears to be little opportunity for female choice in A. fasciatus. However, female mating preferences have even been described for species with clearly male-biased, coercive mating systems (e.g., Poeciliidae; P. sphenops: Gould et al., 1999; Gambusia holbrooki: Bisazza \& Pilastro, 2000; Bisazza et al., 2001; P. mexicana: Plath et al., 2004, 2005). Apparently, that females of such species often cannot choose due to male coercion does not mean that they have not evolved mating preferences.

\section{Acknowledgements}

We thank H. Wilkens for access to his fish stocks and J. Parzefall for helpful discussions. M. Tobler and A. Weber kindly read an earlier version of this manuscript. T.H. Dirks, I.D. Schmidt and the aquarium team in Hamburg provided technical support and animal care. The experiments reported in this paper comply with the current laws of Germany.

\section{References}

Alvarez, J. (1946). Revisión del genero Anoptichthys con descriptión de una especia nueva (Pisces, Characidae). - Ann. Esc. Nac. Cien. Biol. 4: 263-282. 
Andersson, M. (1994). Sexual selection. - Princeton University Press, Princeton.

Aspbury, A.S. \& Gabor, C.R. (2004). Differential sperm priming by male sailfin mollies (Poecilia latipinna): effects of female and male size. - Ethology 110: 193-202.

Avise, J.C. \& Selander, R.K. (1972). Evolutionary genetics of cave-dwelling fishes of the genus Astyanax. — Evolution 26: 1-19.

Behrens, M., Langecker, T.G., Wilkens, H. \& Schmale, H. (1997). Comparative analysis of pax-6 sequences and expression in the eye development of the blind cave fish Astyanax fasciatus and its epigean conspecific. - Mol. Biol. Evol. 14: 299-308.

Bisazza, A. \& Pilastro, A. (2000). Variation of female preference for male coloration in the eastern mosquitofish Gambusia holbrooki. — Behav. Genet. 30: 207-212.

Bisazza, A., Vaccari, G. \& Pilastro, A. (2001). Female mate choice in a mating system dominated by sexual coercion. - Behav. Ecol. 12: 59-64.

Borowsky, R. \& Wilkens, H. (2002). Mapping a cave fish genome: polygenic systems and regressive evolution. - J. Hered. 93: 19-21.

Breder (1943). A note on erratic viciousness in Astyanax fasciatus (Philippi). - Copeia 2: 82-84.

Burchards, H., Dölle, A. \& Parzefall, J. (1985). Aggressive behavior of an epigean population of Astyanax fasciatus (Characidae, Pisces) and some observations of three subterranean populations. - Behav. Process. 11: 225-235.

Burr, B.M., Adams, G.L., Krejca, I.K., Paul, R.I., Warren, M.L. (2001). Troglomorphic sculpins of the Cottus carolinae species group in Perry County, Missouri: distribution, external morphology, and conservational status. — Environ. Biol. Fish. 62: 279-296.

Bussing, W.A. (1998). Peces de las aguas continentales de Costa Rica - Freshwater fishes of Costa Rica. - Editorial de la Universidad de Costa Rica, San José.

Caccone, A. \& Sbordoni, V. (2001). Molecular biogeography of cave life: a study using mitochondrial DNA from bathysciine beetles. - Evolution 55: 122-130.

Couldridge, V.C.K. \& Alexander, G.J. (2001). Does time spent near a male predict female mate choice in a Malawian cichlid? - J. Fish Biol. 59: 667-672.

Chu, S.-L. \& Chen, Y.R. (1979). A new blind cobitid fish (Pisces, Cypriniformes) from subterranean waters in Yunnan, China. - Acta Zool. Sin. 25: 285-287. (Chinese text).

Culver, D.C. (1982). Cave life: Evolution and ecology. - Harvard University Press, Cambridge, MA.

Culver, D.C. \& Wilkens, H. (2000). Critical review of the relevant theories of the evolution of subterranean animals. - In: Ecosystems of the world, Vol. 30: Subterranean ecosystems (Wilkens, H., Culver, D.C. \& Humphreys, W.F., eds). Elsevier, Amsterdam, p. 381-398.

Culver, D.C., Kane, T.C. \& Fong, D.W. (1995). Adaptation and natural selection in caves. Harvard University Press, Cambridge, London.

Darwin, C. (1859). On the origin of species. - John Murray, London.

Dowling, T.E., Martasian, D.P. \& Jeffery, W.R. (2002). Evidence for multiple genetic lineages with similar eyeless phenotypes in blind cavefish, Astyanax fasciatus. - Mol. Biol. Evol. 19: 446-455.

Espinasa, L. \& Borowsky, R. (2001). Origins and relationships of cave populations of the blind Mexican tetra, Astyanax fasciatus, in the Sierra de El Abra. - Environ. Biol. Fish. 62: 233-237.

Espinasa, L., Rivas-Manzano, P. \& Espinosa Perez, H. (2001). A new blind cavefish population of the genus Astyanax: geography, morphology and behavior. - Environ. Biol. Fish. 62: 339-344. 
Freemann, S., Herron, J. (2001). Evolutionary analysis, second edition. — Pearson International.

Futuyma, D.J. (1998). Evolutionary biology, third edition. - Sinauer, Sunderland, M.A.

Gonçalves, D.M. \& Oliveira, R.F. (2003). Time spent close to a sexual partner as a measure of female mate preference in a sex-role-reversed population of the blenny Salaria pavo (Risso) (Pisces: Blenniidae). - Acta Ethol. 6: 1-5.

Gould, J.L., Zabka, T.S., Malizia, R.W., Park, A. \& Mukerji, J. (1999). Possible decisionmaking preadaptations in the molly Poecilia sphenops. - Anim. Cogn. 2: 91-95.

Hassan, E.S. (1989). Hydrodynamic imaging of the surroundings by the lateral line of the blind cave fish Anoptichthys jordani. - In: The mechanosensory lateral line neurobiology and evolution (Coombs, S., Gorner, P. \& Munz, H., eds). Springer-Verlag, New York, p. 217-228.

Hüppop, K. (1987). Food-finding ability in cave fish (Astyanax fasciatus). — Int. J. Speleol. 16: 59-66.

Jeffery, W.R. (2001). Cavefish as model system in evolutionary developmental biology. Develop. Biol. 231: 1-12.

Jeffery, W.R. (2005). Adaptive evolution of eye degeneration in the Mexican blind cavefish. — J. Hered. 96: 185-196.

Kodric-Brown, A. (1992). Male dominance can enhance mating success in guppies. - Anim. Behav. 44: 165-167.

Marco, A., Chivers, D.P., Kiesecker, J.M. \& Blaustein, A.R. (1998). Mate choice by chemical cues in the western redback (Plethodon vehiculum) and Dunn's ( $P$. dunni) salamanders. — Ethology 104: 781-788.

Miller, R.R. (1986). Composition and derivation of the fresh water fish fauna of Mexico. Ann. Esc. Nac. Cien. Biol. 30: 121-153.

Mitchell, R.W., Russell, W.H. \& Elliott, W.R. (1977). Mexican eyeless characin fishes, genus Astyanax: Environment, distribution and evolution. - Spec. Publ. Mus. Tex. Techn. Univ. 12: 1-89.

Montgomery, J.C., Coombs, S. \& Baker, C.F. (2001). The mechanosensory lateral line system of the hypogean form of Astyanax fasciatus. — Environ. Biol. Fish. 62: 87-96.

Panaram, K. \& Borowski, R. (2005). Gene flow and genetic variability in cave and surface populations of the Mexican tetra, Astyanax mexicanus (Teleostei: Characidae). Copeia 2005: 409-416.

Parry, J.W.L., Peirson, S.N., Wilkens, H. \& Bowmaker, J.K. (2003). Multiple photopigments from the Mexican blind cavefish, Astyanax fasciatus: a microspectrophotometric study. — Vision Res. 43: 31-41.

Parzefall, J. (1970). Morphologische Untersuchungen an einer Höhlenform von Mollienesia sphenops (Pisces, Poeciliidae). — Z. Morphol. Tiere 68: 323-342.

Parzefall, J. (1983). Field observations in epigean and cave populations of the Mexican characid Astyanax fasciatus (Pisces, Characidae) — Mem. Biospeol. 10: 171-176.

Parzefall, J. (1993a). Schooling behavior in population-hybrids of Astyanax fasciatus and Poecilia mexicana (Pisces, Characidae and Poeciliidae). — In: Trends in ichthyology: An international perspective (Schröder, H., Bauer, J. \& Schartl, M., eds). Blackwell Scientific, Oxford, p. 297-303.

Parzefall, J. (1993b). Behavioral ecology of cave-dwelling fishes. — In: Behavior of teleost fishes, second edition (Pitcher, T.J., ed.). Chapman and Hall, London, p. 573-608. 
Parzefall, J. \& Senkel, S. (1986). Schooling behavior in cavernicolous fish and their epigean conspecifics. - In: 9 Congres International de Espeleologica, Barcelona, p. 107-109.

Parzefall, J. \& Hausberg, C. (2001). Ontogeny of the aggressive behavior in epigean and hypogean populations of Astyanax fasciatus (Characidae, Teleostei) and their hybrids. - Mem. Biospeol. 28: 157-161.

Peters, N., Scholl, A. \& Wilkens, H. (1975). Der Micos-Fisch, Höhlenfisch in statu nascendi oder Bastard? Ein Beitrag zur Evolution der Höhlentiere. - Z. Zool. Syst. Evolutionsforsch. 13: 110-124.

Plath, M., Körner, K.E., Parzefall, J. \& Schlupp, I. (2003). Persistence of a visually mediated mating preference in the Cave molly, Poecilia mexicana (Poeciliidae, Teleostei). Subterran. Biol. 1: 93-97.

Plath, M., Parzefall, J., Körner, K.E. \& Schlupp, I. (2004). Sexual selection in darkness: Female mating preferences in surface- and cave-dwelling Atlantic mollies, Poecilia mexicana (Poeciliidae, Teleostei). — Behav. Ecol. Sociobiol. 55: 596-601.

Plath, M., Heubel, K.U., García de León, F.J. \& Schlupp, I. (2005). Cave molly females (Poecilia mexicana, Poeciliidae, Teleostei) like well fed males. - Behav. Ecol. Sociobiol. 58: 144-151.

Reis, R.E., Kullander, S.O. \& Ferraris, C.J. (2003). The check list of the freshwater fishes of South and Central America. - Edipucrs, Porto Alegre.

Romero, A. (1985). Can evolution regress? — Nat. Speleol. Soc. Bull. 47: 86-88.

Romero, A., Green, S.M., Romero, A., Lelonek, M.M. \& Streponick, K.C. (2003). One eye but no vision: troglomorphic Astyanax fasciatus (Pisces: Characidae) with induced eyes do not respond to light. - J. Exp. Zool. 300B: 72-79.

Ryan, M.J. \& Keddy-Hector, A. (1992). Directional patterns of female mate choice and the role of sensory biases. - Am. Nat. 139: S4-S35.

Schemmel, C. (1967). Vergleichende Untersuchungen an den Hautsinnesorganen ober- und unterirdischer Astyanax-Formen. Ein Beitrag zur Evolution der Cavernicolen. - Z . Morphol. Tiere 61: 255-316.

Schemmel, C. (1980). Studies on the genetics of feeding behavior in the cave fish Astyanax fasciatus f. Anoptichthys. An example of apparent monofactorial inheritance by polygenes. - Z. Tierpsychol. 53: 9-22.

Schlupp, I. \& Plath, M. (2005). Male mate choice and sperm allocation in a sexual/asexual mating complex (Poecilia mexicana, P. formosa, Poeciliidae, Teleostei). - Biol. Lett. 1: $169-171$.

Strecker, U., Bernatchez, L. \& Wilkens, H. (2003). Genetic divergence between cave and surface populations of Astyanax in Mexico (Characidae, Teleostei). - Mol. Ecol. 12: 699-710.

Strecker, U., Faundez, V.H. \& Wilkens, H. (2004). Phylogeography of surface and cave Astyanax (Teleostei) from Central and North America based on cytochrome b sequence data. - Mol. Phylogenet. Evol. 33: 469-481.

Teyke, T. (1990). Morphological differences in neuromasts of the blind cave fish Astyanax hubbsi and the sighted river fish Astyanax fasciatus. - Brain Behav. Evol. 35: 23-30.

Vilella, F.S., Becker, F.G. \& Hartz, S.M. (2002). Diet of Astyanax species (Teleostei, Characidae) in an Atlantic forest river in Southern Brazil. — Brazil. Arch. Biol. Technol. 45: 223-232.

Wilkens, H. (1972). Über Präadaptationen für das Höhlenleben, untersucht am Laichverhalten ober- und unterirdischer Populationen des Astyanax fasciatus. — Zool. Anzeiger 188: $1-11$. 
Wilkens, H. (1988). Evolution and genetics of epigean and cave Astyanax fasciatus (Characidae, Pisces). - Evol. Biol. 23: 271-367.

Wilkens, H. (2001). Convergent adaptations to cave life in the Rhamdia laticauda catfish group (Pimelodidae, Teleostei). — Environ. Biol. Fish. 62: 251-261.

Wilkens, H. \& Burns, R. J. (1972). A new Anoptichthys cave population (Characidae, Pisces) - Annal. Speol. 27: 263-270.

Wilkens, H. \& Hüppop, K. (1986). Sympatric speciation in cave fish? Studies on a mixed population of epi- and hypogean Astyanax (Characidae, Pisces). — Z. Zool. Syst. Evolutionsforsch. 24: 223-230.

Wilkens, H. \& Strecker, U. (2003). Convergent evolution of the cave fish Astyanax (Characidae, Teleostei): genetic evidence from reduced eye-size and pigmentation. - Biol. J. Linn. Soc. 80(4): 545-554.

Yamamoto, Y. \& Jeffery, W.R. (2000). Central role for the lens in cave fish eye degeneration. - Science 289: 631-633.

Yamamoto, Y., Stock, D.W. \& Jeffery, W.R. (2004). Hedgehog signalling controls eye degeneration in blind cavefish. - Nature 431: 844-847. 